\title{
Dural Metastases in Advanced Prostate Cancer: A Case Report and Review of the Literature
}

\author{
Weiner A.B. ${ }^{\mathrm{a}, \mathrm{b}} \quad$ Cortes-Mateus S. ${ }^{\mathrm{b}} \quad$ De Luis E. ${ }^{c} \quad$ Durán I. ${ }^{\mathrm{b}, \mathrm{d}}$ \\ ${ }^{a}$ The University of Chicago Pritzker School of Medicine, Chicago, Ill., USA; ${ }^{b}$ Centro Integral Oncológico Clara Campal; \\ 'Radiology Department, Hospital Madrid-Norte Sanchinarro; ' Facultad de Medicina, Universidad CEU San Pablo, Madrid, Spain
}

\section{Key Words}

Prostatic neoplasm • Metastasis • Dura mater

\begin{abstract}
Dural metastases from advanced prostate cancer are considered an uncommon diagnosis. However, autopsy studies show a high association between advanced prostate cancer and metastases to the meninges. Because the overall survival of advanced prostate cancer patients is expected to improve with the advent of new therapies, the incidence of clinically relevant dural metastases from prostate cancer will likely increase. We present a case of a heavily pre-treated castration-resistant prostate cancer patient who developed metastases to the dura mater. This entity should be considered in the differential diagnosis of any patient with advanced castration-resistant prostate cancer and neurological symptoms. Clinicians should also be aware of the poor prognosis and survival rates associated with the condition.
\end{abstract}

Copyright $\odot 2013$ S. Karger AG, Basel

\section{KARGER}

Fax +4161306 1234

E-Mail karger@karger.ch

www.karger.com
(C) 2013 S. Karger AG, Basel

1015-9770/13/0073-0166\$38.00/0

Accessible online at:

www.karger.com/cur

\section{Case Report}

A 47-year-old male with an unremarkable medical history, presented with increased urinary frequency and a prostate specific antigen (PSA) level of $162 \mathrm{ng} / \mathrm{ml}$. Further studies confirmed the diagnosis of adenocarcinoma of the prostate, Gleason Score 8, stage cT2N1M1 due to pelvic lymph node and bony metastases. The patient was then started on complete androgen blockade with goserelin and bicalutamide. In May 2008 the disease was considered castration resistant and chemotherapy with docetaxel and prednisone was initiated along with 3-weekly bisphosphonates. The patient required second line treatment with mitoxantrone and prednisone that added limited clinical and PSA benefit. In August 2009 the PSA was $1,210 \mathrm{ng} / \mathrm{ml}$ and the patient had diffuse bone pain. On radiologic evaluation bony, lymph node, and liver metastases were observed. After 3 cycles of weekly paclitaxel the patient presented in clinic with signs of left peripheral facial nerve palsy; neurology consultation confirmed the clinical suspicion and a brain MRI revealed the presence of dural metastases invading the course of the left 7 th cranial nerve (fig. 1). The patient was then started on steroids and sent to the radiation oncology department for palliative treatment. Unfortunately, he died shortly after completing the radiation treatment.

\section{Discussion}

Dural metastasis from metastatic prostate cancer was noted in only 28 of 6,282 patients $(0.04 \%)$ in a single-institution study [1]. However, upon autopsy, dural metastasis can be found in up to $19.5 \%$ of all prostate cancers cases [2]. With recent trials for various new drugs 


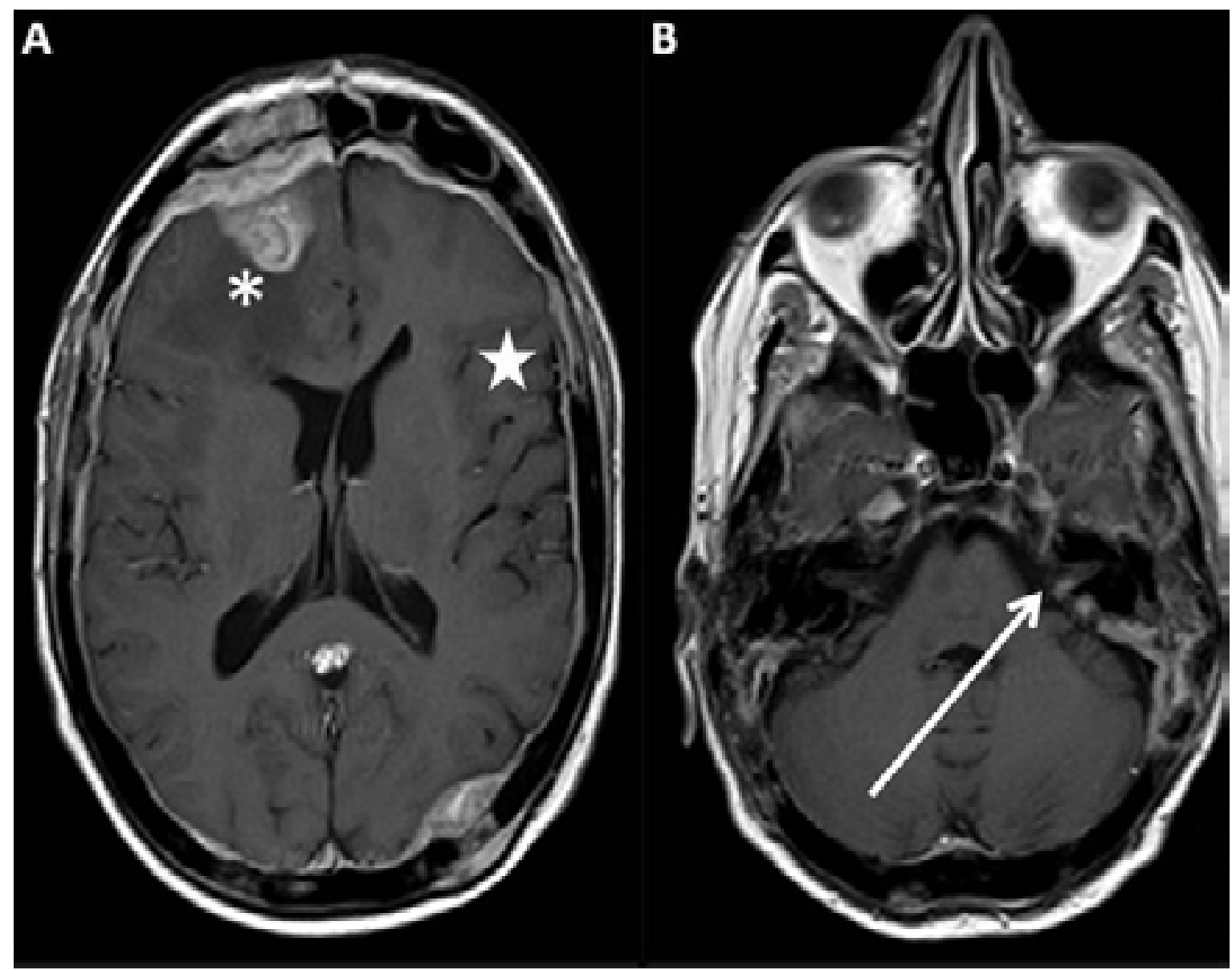

Fig. 1. T1 weighted image after contrast media administration (gadolinium). a Axial scan that shows diffuse dural enhancement (star) and osseous lesions in the calvarium with left occipital dural metastases and left frontal dural lesion (*). b Axial scan showing cerebellum pontine angles. Small metastases within the left internal auditory canal (arrow).

showing improved overall survival for castration-resistant prostate cancer [3], it is likely that more of these previously clinically insignificant cases of dural metastases will become relevant. Thus, an understanding of the proper diagnosis and treatment of dural metastases will become more important in the treatment of advanced prostate cancer.

The most likely form of prostate cancer metastases spread to the dura is hematogenous through the caval system or retrograde seeding by the valveless Batson venous system [2]. The spectrum of symptomatic presentations is wide including increased intracranial pressure, headaches, seizures, cranial nerve palsy, and deteriorating mental state and level of consciousness [4].
A suspicious non-contrast-enhanced CT accompanying the above symptoms warrants contrast-enhanced CT scans or MRI. The former has the advantage of detecting bone involvement while the latter provides better contrast resolution and is considered the superior means of detection of dural metastases and delineation of soft tissue involvement [5]. The most frequent finding is a thickening of the dura mater with intense contrast enhancement. A nodular pattern is also possible [4]. Dural metastases may also induce a classic subdural hematoma [5]. Differential diagnoses should include meningioma, and lymphoma [4].

No standard of treatment has been clearly defined for the management of dural metastases. High dose dexa- 
methasone can produce symptomatic relief even in the absence of cerebral edema [6] and evacuation of symptomatic subdural hematoma should be considered. Surgical resection is rarely performed and is only reserved for single metastatic lesions causing severe symptoms [7]. Stereotactic radiosurgery either alone or in combination with whole brain radiotherapy seems to be a safe and effective treatment option [8]. In spite of various treatment options, the outcome of patients with advanced cancer and dural metastasis is poor with an estimated median survival of 3 to 4 months [9].
In conclusion, metastases to the dura mater should be considered in the differential diagnosis of any patient with advanced castration-resistant prostate cancer and neurological symptoms. This entity will probably become more frequent as overall survival of advanced prostate cancer patients improves. A prompt diagnosis should lead to an appropriate treatment. In addition, clinicians should note the poor prognosis and survival rate associated with the condition.

\section{References}

1 Tremont-Lukats IW, Bobustuc G, Lagos GK, Lolas K, Kyritsis AP, Puduvalli VK: Brain metastasis from prostate carcinoma: the $\mathrm{M}$. D. Anderson Cancer Center experience. Cancer 2003;98:363-368.

2 Bubendorf L, Schopfer A, Wagner U, Sauter G, Moch H, Willi N, Gasser TC, Mihatsch MJ: Metastatic patterns of prostate cancer: an autopsy study of 1,589 patients. Hum Pathol 2000;31:578-583.

3 Sridhar SS, Freedland SJ, Gleave ME, Higano C, Mulders P, Parker C, Sartor O, Saad F: Castration-resistant prostate cancer: from new pathophysiology to new treatment. Eur Urol 2013.
4 de Vasconcelos Sobreira Guedes B, da Rocha AJ, Gama HP, da Silva CJ: Dural metastases from prostate carcinoma: a systematic review of the literature apropos of six patients. Eur J Radiol 2011;80:236-240.

5 Yu WL, Sitt CM, Cheung TC: Dural metastases from prostate cancer mimicking acute sub-dural hematoma. Emerg Radiol 2012;19: 549-552.

6 Bentley AM, Keen JC: Dural metastases in prostate cancer. Clin Oncol (R Coll Radiol) 2003;15:165-166.
7 Levitt MR, Levitt R, Silbergeld DL: Controversies in the management of brain metastases. Surg Neurol Int 2013;4(suppl 4):S231235.

8 Patil CG, Pricola K, Sarmiento JM, Garg SK, Bryant A, Black KL: Whole brain radiation therapy (WBRT) alone versus WBRT and radiosurgery for the treatment of brain metastases. Cochrane Database Syst Rev 2012;9: CD006121.

9 Nayak L, Abrey LE, Iwamoto FM: Intracranial dural metastases. Cancer 2009;115:19471953. 